\title{
Uncontrolled hypertension among tobacco-users: women of prime childbearing age at risk in India
}

\author{
Biplab K. Datta ${ }^{1,2}$ and Muhammad J. Husain ${ }^{1 *}$ (i)
}

\begin{abstract}
Background: Uncontrolled hypertension and tobacco use are two major public health issues that have implications for reproductive outcomes. This paper examines the association between tobacco-use status and uncontrolled hypertension among prime childbearing age (20-35) women in India.

Methods: We used the India National Family Health Survey (NFHS-4) 2015-2016 to obtain data on hypertension status and tobacco use for 356,853 women aged 20-35. We estimated multivariate logistic regressions to obtain the adjusted odds ratio for tobacco users in favor of having uncontrolled hypertension. We examined the adjusted odds at different wealth index quintiles, at different educational attainment, and at different level of nutritional status measured by body mass index.

Results: We found that the odds of having uncontrolled hypertension for the tobacco user women in India was 1.1 ( $95 \% \mathrm{Cl}: 1.01-1.19$ ) times that of tobacco non-users at prime childbearing age. The odds were higher for tobaccousers at the poorest quintile (1.27,95\% Cl: 1.14-1.42) and with no education (1.22,95\% Cl: 1.10-1.34). The odds were also higher for tobacco-users who were overweight (1.88, 95\% Cl: $1.57-2.29)$ or obese (2.82, 95\% Cl: 1.88-4.24).

Conclusions: Our findings highlight the disproportionate dual risk of uncontrolled hypertension and tobacco use among lower-income women of prime childbearing age, identifying an opportunity for coordinated tobacco control and hypertension prevention initiatives to ensure better health of reproductive-age women in India.
\end{abstract}

Keywords: Hypertension, Tobacco, Childbearing age, India

\section{Background}

Hypertension or elevated blood pressure is the most significant risk factor for almost all cardiovascular diseases (CVD) [1], the number one cause of death worldwide [2]. Uncontrolled hypertension is associated with an increased risk of CVD-specific mortality [3]. In addition to the risk of CVD, hypertension in women of childbearing age may complicate pregnancy and affect childbirth

\footnotetext{
*Correspondence: mhusain@cdc.gov

${ }^{1}$ Global Noncommunicable Diseases Branch, Division of Global Health Protection, Center for Global Health, Centers for Disease Control and Prevention, 1600 Clifton Road, Atlanta, GA 30329, USA

Full list of author information is available at the end of the article
}

outcomes [4]. Tobacco use, both smoking and smokeless, is a risk factor for elevated blood pressure [5-7]. Tobacco use is also associated with increased risk of infertility, certain birth defects and adverse birth outcomes [8]. Both uncontrolled hypertension and tobacco use, thus have implications for childbearing-age women's health and pregnancy outcomes.

The literature on tobacco use among childbearing-age women and hypertension in childbearing-age women separately examines the prevalence and determinants of each condition. Studies explore socioeconomic patterns of tobacco consumption [9], tobacco use during pregnancy [10], types of tobacco use (smoking- or 
smokeless-tobacco) and geographic correlates [11, 12], educational and wealth inequalities [13] associated with tobacco use, and the association of tobacco use with child mortality [14], food insecurity [15], and intimate partner violence [16]. Studies on hypertension investigate hypertension awareness and control among reproductive-age women [17], urban-rural [18] and cross-country [19] differences in prevalence, risk factors associated with undiagnosed hypertension [20], and the association of hypertensive condition with obesity [21], socioeconomic gradients [22], wealth and education-based inequalities [23], and household environment [24]. Though certain aspects of tobacco use and hypertension in reproductive-age women were studied individually, there is a gap in terms of assessing the dual risk of tobacco use and uncontrolled hypertension.

One such entwined aspect previously not explored in literature is whether women of prime childbearing age (20-35), who consume tobacco products, have an added risk of being hypertensive and not having it under control. Childbearing during adolescent age (15-19) has certain risks and complications [25]. Giving birth at advanced maternal age (over 35) is also associated with adverse pregnancy outcomes [26]. On the other hand, childbearing during age $20-35$ is comparatively safe and regarded optimal for pregnancy outcomes [27]. In the absence of maternal age gradient being a prominent risk factor, uncontrolled hypertension among tobacco user women has implications for reproductive health outcomes in this age group.

We explore this issue using data from India, the second-most populous country in the world, where female tobacco use, hypertension, and child and maternal health are critical public health issues. India has a very large tobacco-user female population with approximately 65 million (14.2\%) women aged 15 and older consuming smoking and/or smokeless tobacco [28]. A recent study estimates that 95 million (20.0\%) women aged 18 and older in India are hypertensive [29]. Among the reproductive-age females, nearly half are unaware of their hypertension status, and only one quarter receive treatment for lowering blood pressure or have their blood pressure under control [17]. Hypertensive disorders in pregnancy, which are linked to pre-existing hypertension [30], are among the leading causes of maternal death in India [31]. India also has the highest number of stillbirths globally [32], for which hypertension [33] and tobacco use [34] are critical risk factors. The adverse health outcomes of uncontrolled hypertension among childbearing-age women can be further aggravated by tobacco use, and vice versa.

Given the consequences of tobacco use and uncontrolled hypertension concerning maternal and child health, this study aims to assess the population level joint risk of tobacco use and uncontrolled hypertension in women at their prime age of childbearing. More than $75 \%$ of the births in India occur at mothers' prime childbearing age [35], and, therefore, it is worthwhile to understand any population level risks that may impact pregnancy outcomes. Knowledge about whether a tobacco user female has an added risk of uncontrolled hypertension, thus have important implications for effectively managing maternal and child healthcare, particularly in a low resource setting. To the best of our knowledge, this is the first study to assess the joint risk of tobacco use and uncontrolled hypertension in women of prime childbearing age in a developing country. The findings of this analysis can inform policies for integrated and coordinated hypertension management and tobacco control strategies targeted toward childbearing-age women in developing countries.

\section{Methods \\ Data}

We used data from the National Family Health Survey (NFHS-4) 2015-2016 of India, a nationally representative survey that reports indicators of tobacco use and hypertension in reproductive-age women [35]. For our analysis, we obtained the tobacco use and hypertension status of 356,853 women aged 20-35. NFHS-4 collected self-reported information on respondents' current use of smoked tobacco products (e.g., cigarette, bidi, cigar, pipe, hookah) and smokeless tobacco products (e.g., paan masala or gutkha, khaini, paan with tobacco, chewing tobacco, snuff, and other). The survey also provides blood pressure measures of reproductive-age women. Respondents' systolic blood pressure (SBP) and diastolic blood pressure (DBP) were measured three times during a single visit with at least five minutes interval between each measure. Survey protocols of the NFHS-4, which is part of the USAID's Demographic and Health Surveys (DHS) program, were reviewed and approved by the ICF Institutional Review Board (IRB). Details of the ethical review are available at: https://dhsprogram.com/What-We-Do/ Protecting-the-Privacy-of-DHS-Survey-Respondents. $\mathrm{cfm}$.

\section{Measurement}

The NFHS-4 questionnaire asks whether the respondent currently smokes or uses tobacco in any other form. An individual was identified as a tobacco user if she reported current (at the time of the survey) consumption of one or more of the tobacco products mentioned above. For hypertensive condition, individuals with SBP $\geq 140 \mathrm{mmHg}$ or DBP $\geq 90 \mathrm{mmHg}$ were identified to have uncontrolled hypertension. We applied the 
following algorithm that replicates the estimates in the NFHS-4 final report to account for SBP and DBP for each woman: we took the "first measure" if available and the second and third measures were missing $(1.1 \%$ of the sample); the "second measure" if available and the third measure was missing ( $1.9 \%$ of the sample); the "third measure" if available and the second measure was missing $(0.2 \%$ of the sample); and the average of the "second and third measures" if both were available $(94.3 \%$ of the sample) [35].

\section{Statistical analysis}

Using the NHFS-4 data, we estimated differences in uncontrolled hypertension prevalence between tobacco user and non-user females. We examined these differences by wealth index quintiles for the full sample and for urban and rural sub-samples. These differences, however, do not account for the sociodemographic characteristics of the respondents. To obtain adjusted measures of differences in uncontrolled hypertension status between the tobacco-user and non-user groups, we estimated a multivariate logistic model. Our outcome variable is a binary variable indicating whether the respondent had uncontrolled hypertension or not. The tobacco use variable is denoted by another binary variable indicating any tobacco (smoking or smokeless) product consumption by the respondent at the time of the survey.

We controlled for a rich set of covariates including age group (20-24 (base category), 25-29, or 30+), respondent's nutritional status measured by body mass index (BMI) categories (underweight: $<18.5 \mathrm{~kg} / \mathrm{m}^{2}$, normal: $18.5-24.9 \mathrm{~kg} / \mathrm{m}^{2}$ (base category), overweight: $25.0-29.9$ $\mathrm{kg} / \mathrm{m}^{2}$, or obese: $\geq 30.0 \mathrm{~kg} / \mathrm{m}^{2}$ ), wealth index quintiles (base category: 1st quintile), educational attainment (no education (base category), primary, secondary, or higher), current marital status (never married (base category), currently married, or widowed/divorced/separated), and urban or rural residence. We also controlled for state fixed effects to control for state-level variations in women's health-related issues in India. The multivariate logistic model was separately estimated for the full sample, and for urban and rural sub-samples using complex survey weights. The adjusted odds ratios in favor of having uncontrolled hypertension were reported.

Next, we examined the adjusted odds ratios for the tobacco use variable in favor of having uncontrolled hypertension at different wealth index quintiles, at different levels of educational attainment, and at different levels of nutritional status (measured by BMI). For these analyses, we interacted the tobacco-use indicator with respective indicator variables and estimated separate multivariate logistic specifications for each indicator (i.e., wealth index, educational attainment, and BMI group). The exponentiated value of the coefficient of the interaction term is the adjusted odds ratio for the tobacco use variable at the respective category of the respective indicator.

The set of sociodemographic controls excludes the $j$ th indicator for respective specifications. For example, it does not include wealth index quintiles while the model was estimated to examine the odds ratios of tobacco use at different wealth index quintiles. Lastly, we estimated the multivariate logistic specification for mutually exclusive tobacco-use categories by replacing "any tobacco-use" indicator with three types of tobacco-use indicators-"smoking-only", "smokeless-only", and "dualuse". All these specifications were estimated for the full sample and urban and rural sub-samples using complex survey weights.

\section{Results \\ Descriptive analysis}

In the NFHS-4, $5.4 \%$ of the prime childbearing-age women reported some kind of tobacco use (smoking and/or smokeless). More than $80 \%$ of the tobacco users consumed smokeless tobacco only, nearly $16 \%$ consumed smoking tobacco only, and around $2 \%$ consumed both smoking and smokeless tobacco (dual-use). Tobacco use among prime childbearing-age women in India was more prevalent in the rural areas than in urban areas, and in the poorest quintiles than in wealthier quintiles (Table 1). Nearly half of the tobacco users did not have any formal education. Tobacco use was more prevalent in the older (age $30+$ ) age group, and almost $90 \%$ of the tobacco users were married at the time of the survey.

\section{Bivariate analysis}

From the blood pressure measures, it was estimated that around $6 \%$ of the age $20-35$ females in India had uncontrolled hypertension. However, among tobacco users, this rate was as high as $8 \%$. Figure 1 shows the differences in uncontrolled hypertension prevalence between tobacco users and non-users across wealth index quintiles. The difference in uncontrolled hypertension prevalence ranges from 1.7 to 3.3 percentage points across quintiles. The gap exists at every wealth quintile in both urban and rural areas except the urban top quintile where the prevalence is higher among tobacco non-users. This may be due to very low level of tobacco consumption at the urban top quintile $(0.70 \%)$ and proportionately fewer hypertensive cases in this small group.

\section{Multivariate analysis}

Table 2 presents the adjusted odds ratios in favor of having uncontrolled hypertension. The odds of having uncontrolled hypertension for tobacco users was 1.10 
Table 1 Descriptive statistics by tobacco user and non-user

\begin{tabular}{|c|c|c|c|}
\hline & Non-user & Tobacco-user & All \\
\hline & Share (\%) & & \\
\hline \multirow[t]{2}{*}{ Urban } & 34.97 & 22.41 & 34.29 \\
\hline & $(34.52,35.41)$ & $(21.29,23.54)$ & $(33.85,34.73)$ \\
\hline \multicolumn{4}{|l|}{ Age group } \\
\hline \multirow[t]{2}{*}{$20-24$} & 34.63 & 19.79 & 33.82 \\
\hline & $(34.38,34.88)$ & $(19.07,20.52)$ & $(33.58,34.07)$ \\
\hline \multirow[t]{2}{*}{$25-29$} & 31.75 & 30.65 & 31.69 \\
\hline & $(31.52,31.99)$ & $(29.75,31.56)$ & $(31.46,31.92)$ \\
\hline \multirow[t]{2}{*}{$30+$} & 33.62 & 49.55 & 34.48 \\
\hline & $(33.36,33.87)$ & $(48.53,50.57)$ & $(34.24,34.73)$ \\
\hline \multicolumn{4}{|l|}{ Nutritional status } \\
\hline \multirow[t]{2}{*}{ Normal (BMI 18.5-24.9) } & 60.37 & 57.48 & 60.21 \\
\hline & $(60.10,60.65)$ & $(56.58,58.38)$ & $(59.95,60.48)$ \\
\hline \multirow[t]{2}{*}{ Underweight $(\mathrm{BMI}<18.5)$} & 20.86 & 31.52 & 21.43 \\
\hline & $(20.63,21.08)$ & $(30.67,32.37)$ & $(21.21,21.65)$ \\
\hline \multirow[t]{2}{*}{ Overweight (BMI 25.0-29.9) } & 14.63 & 8.88 & 14.32 \\
\hline & $(14.42,14.84)$ & $(8.32,9.44)$ & $(14.12,14.53)$ \\
\hline \multirow{2}{*}{ Obese (BMI $\geq 30.0)$} & 4.14 & 2.12 & 4.03 \\
\hline & $(4.01,4.27)$ & $(1.80,2.44)$ & $(3.90,4.16)$ \\
\hline \multicolumn{4}{|l|}{ Wealth index quintile } \\
\hline \multirow[t]{2}{*}{ 1st Quintile } & 16.38 & 40.08 & 17.67 \\
\hline & $(16.13,16.64)$ & $(39.07,41.09)$ & $(17.41,17.93)$ \\
\hline \multirow[t]{2}{*}{ 2nd Quintile } & 18.83 & 28.19 & 19.34 \\
\hline & $(18.58,19.09)$ & $(27.36,29.02)$ & $(19.09,19.59)$ \\
\hline \multirow[t]{2}{*}{ 3rd Quintile } & 20.93 & 17.59 & 20.75 \\
\hline & $(20.66,21.21)$ & $(16.83,18.34)$ & $(20.49,21.02)$ \\
\hline \multirow[t]{2}{*}{ 4th Quintile } & 22.18 & 10.03 & 21.53 \\
\hline & $(21.87,22.50)$ & $(9.32,10.74)$ & $(21.21,21.84)$ \\
\hline \multirow[t]{2}{*}{ 5th Quintile } & 21.66 & 4.12 & 20.71 \\
\hline & $(21.26,22.07)$ & $(3.61,4.62)$ & $(20.32,21.10)$ \\
\hline \multicolumn{4}{|l|}{ Education } \\
\hline \multirow[t]{2}{*}{ No education } & 21.99 & 48.27 & 23.42 \\
\hline & $(21.73,22.26)$ & $(47.17,49.37)$ & $(23.15,23.70)$ \\
\hline \multirow[t]{2}{*}{ Primary } & 12.48 & 20.76 & 12.93 \\
\hline & $(12.29,12.67)$ & $(20.01,21.51)$ & $(12.74,13.11)$ \\
\hline \multirow{2}{*}{ Secondary } & 46.79 & 28.81 & 45.82 \\
\hline & $(46.45,47.14)$ & $(27.85,29.77)$ & $(45.48,46.15)$ \\
\hline \multirow[t]{2}{*}{ Higher } & 18.73 & 2.16 & 17.83 \\
\hline & $(18.42,19.05)$ & $(1.83,2.48)$ & $(17.53,18.14)$ \\
\hline \multicolumn{4}{|l|}{ Marital status } \\
\hline \multirow[t]{2}{*}{ Never in union } & 15.06 & 6.48 & 14.60 \\
\hline & $(14.84,15.28)$ & $(6.00,6.96)$ & $(14.39,14.81)$ \\
\hline Married & 82.58 & 88.71 & 82.91 \\
\hline & $(82.35,82.81)$ & $(88.09,89.34)$ & $(82.69,83.14)$ \\
\hline Widowed, divorced/sepa- & 2.36 & 4.81 & 2.49 \\
\hline & $(2.27,2.44)$ & $(4.40,5.21)$ & $(2.41,2.57)$ \\
\hline Observations & 323,937 & 32,916 & 356,853 \\
\hline
\end{tabular}

$95 \%$ confidence intervals are in parenthesis

Estimates were obtained using complex survey weights times that of tobacco non-users. The odds were slightly lower in the rural areas (1.08) and slightly higher (1.15) though not statistically significant $(p=0.202)$ in the urban areas. These outcomes were adjusted for potential confounders such as age, wealth, and education. Among other covariates, the odds were higher for the older age individuals compared to age 20-24, and for overweight and obese individuals compared to individuals of normal BMI.

Across the wealth index quintiles, the odds of having uncontrolled hypertension for tobacco users were the highest (1.27) at the poorest (1st) quintile (Fig. 2). The odds were also highest (1.33) at the poorest (1st) quintile in the rural areas. Among urban quintiles the odds were the highest (1.65) at the middle (3rd) quintile and the lowest at the top (5th) quintile. These outcomes were adjusted for potential confounders such as age and education.

The odds of having uncontrolled hypertension for tobacco users were the highest (1.22) for individuals having no formal education (Fig. 3). However, for the urban sub-sample, the odds were the highest (1.41) for individuals with secondary level of education. The odds for the higher educated group were lower and statistically insignificant for both urban and rural sub-groups. These outcomes were adjusted for potential confounders such as age and wealth.

The odds were the highest (2.82) for obese tobacco users followed by overweight tobacco users (1.90) and the lowest (0.74) for the underweight tobacco users (Fig. 4). The findings were consistent in both urban and rural sub-samples. These outcomes were adjusted for probable confounders such as age, wealth, and education.

Finally the odds for users of smokeless-only were 1.10 times of that of the tobacco non-users in the full sample as well as in the rural sub-sample (Fig. 5). The odds for smokeless-only use were not statistically significant $(p=0.437)$ in the urban sub-sample. The odds for dual-use were higher across all samples but not statistically significant ( $p$ value ranges from 0.222 to 0.283 ). The odds for smoking-only were, however, higher $(1.51, p=0.103)$ in the urban sub-sample.

\section{Discussion}

This paper investigated the association between two important public health issues-uncontrolled hypertension and tobacco use among prime childbearing-age women in India. We, however, do not study whether tobacco use causes hypertension. Rather we examine whether tobacco-user women in India at their prime age of childbearing have an additional risk of uncontrolled hypertension. We find that there is a statistically significant association between being 


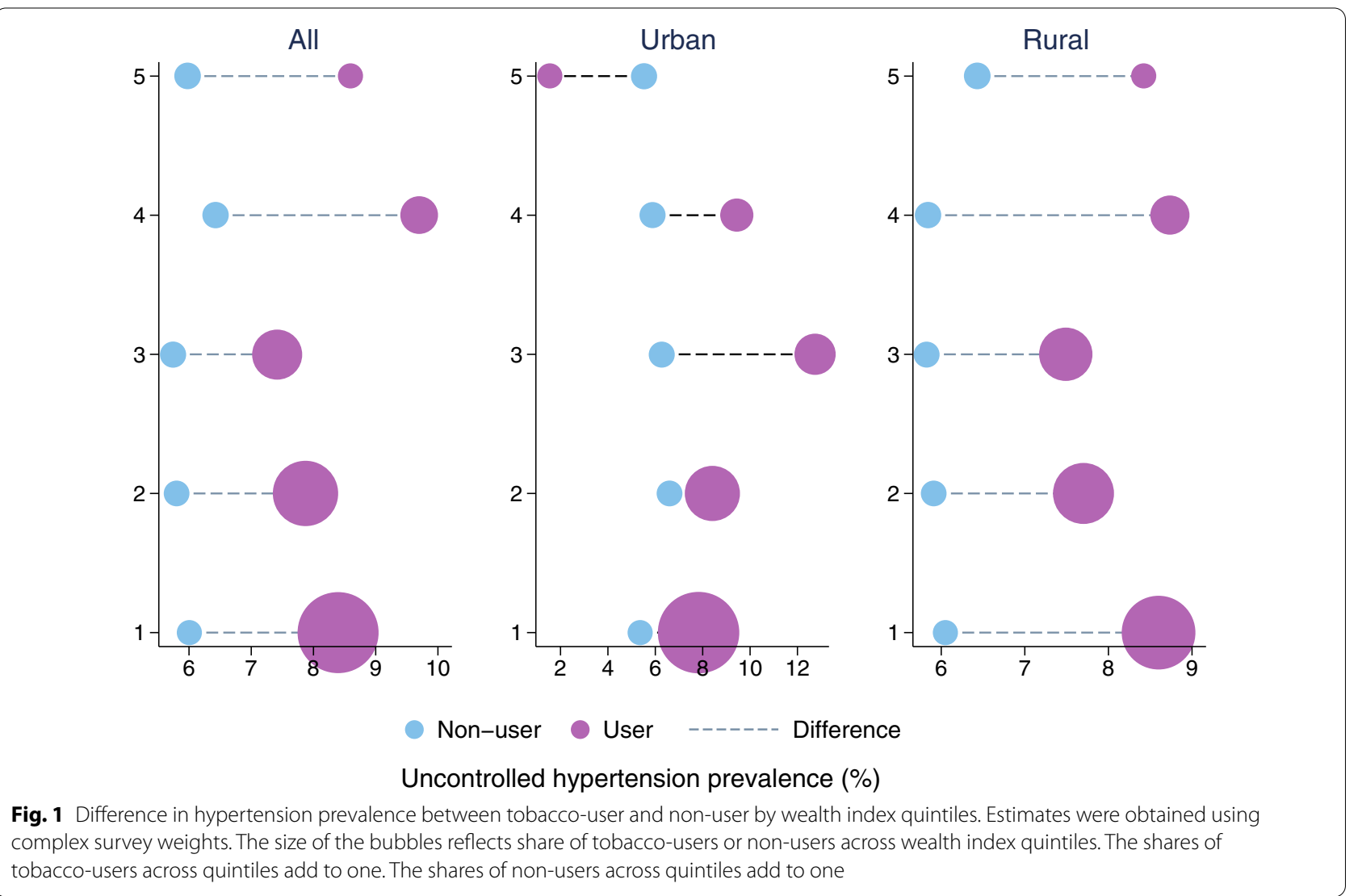

a tobacco user and having uncontrolled hypertension among women aged 20-35. Our findings describe the dual problem of uncontrolled hypertension in prime childbearing age women in India who use tobacco products, demonstrating the need for greater access and utilization of hypertension care in this group.

Childbearing-age tobacco-user females in India predominantly consume smokeless tobacco products. The nicotine, sodium, and licorice contents of smokeless tobacco products can aggravate hypertensive conditions [36]. Prolonged use of smokeless tobacco products is also associated with an increased risk of fatal myocardial infarction and fatal stroke [37]. Despite the adverse health effects of smokeless tobacco use, implementation and enforcement of smokeless tobacco control policies in India remained challenging, mainly because of the fear of economic consequences of job losses among workers in the smokeless tobacco manufacturing sector [36]. Inadequate tobacco control measures to curb smokeless tobacco use may, therefore, contribute to the risk of cardiovascular diseases among childbearing-age women in India. In addition to the adverse reproductive outcomes associated with smokeless tobacco use during pregnancy, the disproportionately high prevalence of uncontrolled hypertension among tobacco users may further compound the risk of adverse pregnancy outcomes.

The greater odds of having uncontrolled hypertension for the tobacco user female at prime age of childbearing could have consequences for infant and maternal health in India, where neonatal mortality (24.9 per 1000 live births) and maternal mortality (130 per 100,000 live births) are serious health concerns $[38,39]$. The association between tobacco use and uncontrolled hypertension represents an additional challenge to safe motherhood in India, motivating policy attention to improving maternal health and childbirth outcomes.

An important aspect of our findings is the relatively higher likelihood of uncontrolled hypertension among overweight and obese tobacco users than non-users. The risk of adverse pregnancy outcomes is higher among obese women [40] and may be further increased by tobacco use and uncontrolled hypertension condition. We also find that the likelihood of having uncontrolled hypertension was relatively higher for tobacco-user women at the lowest wealth 
Table 2 Adjusted odds ratios

\begin{tabular}{|c|c|c|c|}
\hline & All & Urban & Rural \\
\hline Tobacco user & $\begin{array}{l}1.097^{* *} \\
(1.014,1.186)\end{array}$ & $\begin{array}{l}1.151 \\
(0.928,1.428)\end{array}$ & $\begin{array}{l}1.079^{*} \\
(0.998,1.166)\end{array}$ \\
\hline \multicolumn{4}{|l|}{ Age group } \\
\hline $25-29$ & $\begin{array}{l}1.574^{* * *} \\
(1.479,1.675)\end{array}$ & $\begin{array}{l}1.752^{* * *} \\
(1.526,2.011)\end{array}$ & $\begin{array}{l}1.500^{* * *} \\
(1.406,1.601)\end{array}$ \\
\hline $30+$ & $\begin{array}{l}2.576^{* * *} \\
(2.431,2.730)\end{array}$ & $\begin{array}{l}2.953^{* * *} \\
(2.594,3.362)\end{array}$ & $\begin{array}{l}2.422^{* * *} \\
(2.277,2.576)\end{array}$ \\
\hline \multicolumn{4}{|l|}{ Nutritional status } \\
\hline Underweight (BMI < 18.5) & $\begin{array}{l}0.700 * * * \\
(0.662,0.740)\end{array}$ & $\begin{array}{l}0.658^{* * *} \\
(0.562,0.770)\end{array}$ & $\begin{array}{l}0.710^{* * *} \\
(0.669,0.752)\end{array}$ \\
\hline $\begin{array}{l}\text { Overweight (BMl } \\
25.0-29.9)\end{array}$ & $\begin{array}{l}2.170 * * * \\
(2.053,2.295)\end{array}$ & $\begin{array}{l}2.100^{* * *} \\
(1.892,2.330)\end{array}$ & $\begin{array}{l}2.215^{* * *} \\
(2.086,2.352)\end{array}$ \\
\hline Obese (BMI $\geq 30.0)$ & $\begin{array}{l}3.261^{* * *} \\
(2.993,3.553)\end{array}$ & $\begin{array}{l}3.066^{* * *} \\
(2.694,3.489)\end{array}$ & $\begin{array}{l}3.443^{* * *} \\
(3.075,3.855)\end{array}$ \\
\hline \multicolumn{4}{|l|}{ Wealth index quintile } \\
\hline 2nd Quintile & $\begin{array}{l}0.885^{* * *} \\
(0.832,0.941)\end{array}$ & $\begin{array}{l}1.173^{* *} \\
(1.029,1.338)\end{array}$ & $\begin{array}{l}0.901^{* * *} \\
(0.839,0.968)\end{array}$ \\
\hline 3rd Quintile & $\begin{array}{l}0.866^{* * *} \\
(0.810,0.927)\end{array}$ & $\begin{array}{l}1.122^{*} \\
(0.984,1.279)\end{array}$ & $\begin{array}{l}0.853^{* * *} \\
(0.792,0.920)\end{array}$ \\
\hline 4th Quintile & $\begin{array}{l}0.955 \\
(0.886,1.030)\end{array}$ & $\begin{array}{l}1.063 \\
(0.915,1.234)\end{array}$ & $\begin{array}{l}0.869^{* * *} \\
(0.801,0.943)\end{array}$ \\
\hline 5th Quintile & $\begin{array}{l}0.902^{* *} \\
(0.825,0.986)\end{array}$ & $\begin{array}{l}1.056 \\
(0.899,1.239)\end{array}$ & $\begin{array}{l}0.901^{* *} \\
(0.827,0.981)\end{array}$ \\
\hline \multicolumn{4}{|l|}{ Education } \\
\hline Primary & $\begin{array}{l}0.967 \\
(0.907,1.031)\end{array}$ & $\begin{array}{l}0.905 \\
(0.772,1.060)\end{array}$ & $\begin{array}{l}0.987 \\
(0.923,1.056)\end{array}$ \\
\hline Secondary & $\begin{array}{l}0.827^{* * *} \\
(0.782,0.875)\end{array}$ & $\begin{array}{l}0.865^{* *} \\
(0.763,0.981)\end{array}$ & $\begin{array}{l}0.799^{* * *} \\
(0.751,0.850)\end{array}$ \\
\hline Higher & $\begin{array}{l}0.663^{* * *} \\
(0.606,0.726)\end{array}$ & $\begin{array}{l}0.661^{* * *} \\
(0.562,0.778)\end{array}$ & $\begin{array}{l}0.677^{* * *} \\
(0.613,0.748)\end{array}$ \\
\hline \multicolumn{4}{|l|}{ Marital status } \\
\hline Married & $\begin{array}{l}0.848^{* * *} \\
(0.784,0.918)\end{array}$ & $\begin{array}{l}0.826^{* *} \\
(0.713,0.956)\end{array}$ & $\begin{array}{l}0.846^{* * *} \\
(0.778,0.920)\end{array}$ \\
\hline $\begin{array}{l}\text { Widowed, divorced/sepa- } \\
\text { rated }\end{array}$ & $\begin{array}{l}0.949 \\
(0.826,1.089)\end{array}$ & $\begin{array}{l}0.897 \\
(0.699,1.150)\end{array}$ & $\begin{array}{l}0.961 \\
(0.818,1.128)\end{array}$ \\
\hline Urban & $\begin{array}{l}0.915^{* * *} \\
(0.863,0.971)\end{array}$ & & \\
\hline Constant & $\begin{array}{l}0.049^{* * *} \\
(0.037,0.065)\end{array}$ & $\begin{array}{l}0.035^{* * *} \\
(0.021,0.058)\end{array}$ & $\begin{array}{l}0.052^{* * *} \\
(0.038,0.071)\end{array}$ \\
\hline Observations & 356,853 & 103,690 & 253,116 \\
\hline
\end{tabular}

95\% confidence intervals are in parenthesis

Estimates were obtained using complex survey weights

All models control for state fixed effects

${ }^{* * *} p<0.01,{ }^{* *} p<0.05,{ }^{*} p<0.1$ index quintile and with no education, highlighting a source of health disparities in India. There are persistent socioeconomic inequalities in tobacco use prevalence in India, raising questions about the reach of the tobacco control measures to poor and uneducated populations [41]. The association between tobacco use and uncontrolled hypertension, therefore, could further worsen the high burden of adverse health conditions for the socioeconomically disadvantaged populations in India.

One limitation of this analysis is that blood pressure in NHFS-4 was measured during one occasion, which may result in an incorrect determination of hypertension status for some respondents. The data on tobacco use were self-reported, which could be subject to some measurement error. We also do not know if a respondent quit tobacco within weeks or months prior to the interview date. Due to the cross sectional nature of the data we could not offer any causal relationship between tobacco use and uncontrolled hypertension. We also did not analyze the relationship between exposure to secondhand smoking and uncontrolled hypertension, which may be studied in future research. However, despite these limitations we document an important association that has consequences for public health and requires policy attention of the public health practitioners.

\section{Conclusions}

The disproportionately high level of uncontrolled hypertension among prime-childbearing-age women, who consume tobacco, highlights a dual public health risk that motivates health policy attention. The prime childbearing age of $20-35$ is regarded as the safest for pregnancy outcome. We provide evidence that tobacco user women of this age group in India have an additional risk of uncontrolled hypertension, which may exacerbate the health risks of tobacco use concerning child and maternal health. Documentation of this dual risk lays out new avenues of research in public health practice that may lead to better management of maternal and child health issues. Our findings, in general, inform policies for coordinated tobacco control and hypertension prevention initiatives. Tobacco control interventions targeted toward socioeconomically disadvantageous women combined with improved access to hypertension treatment could support efforts to improve health outcomes in India. 


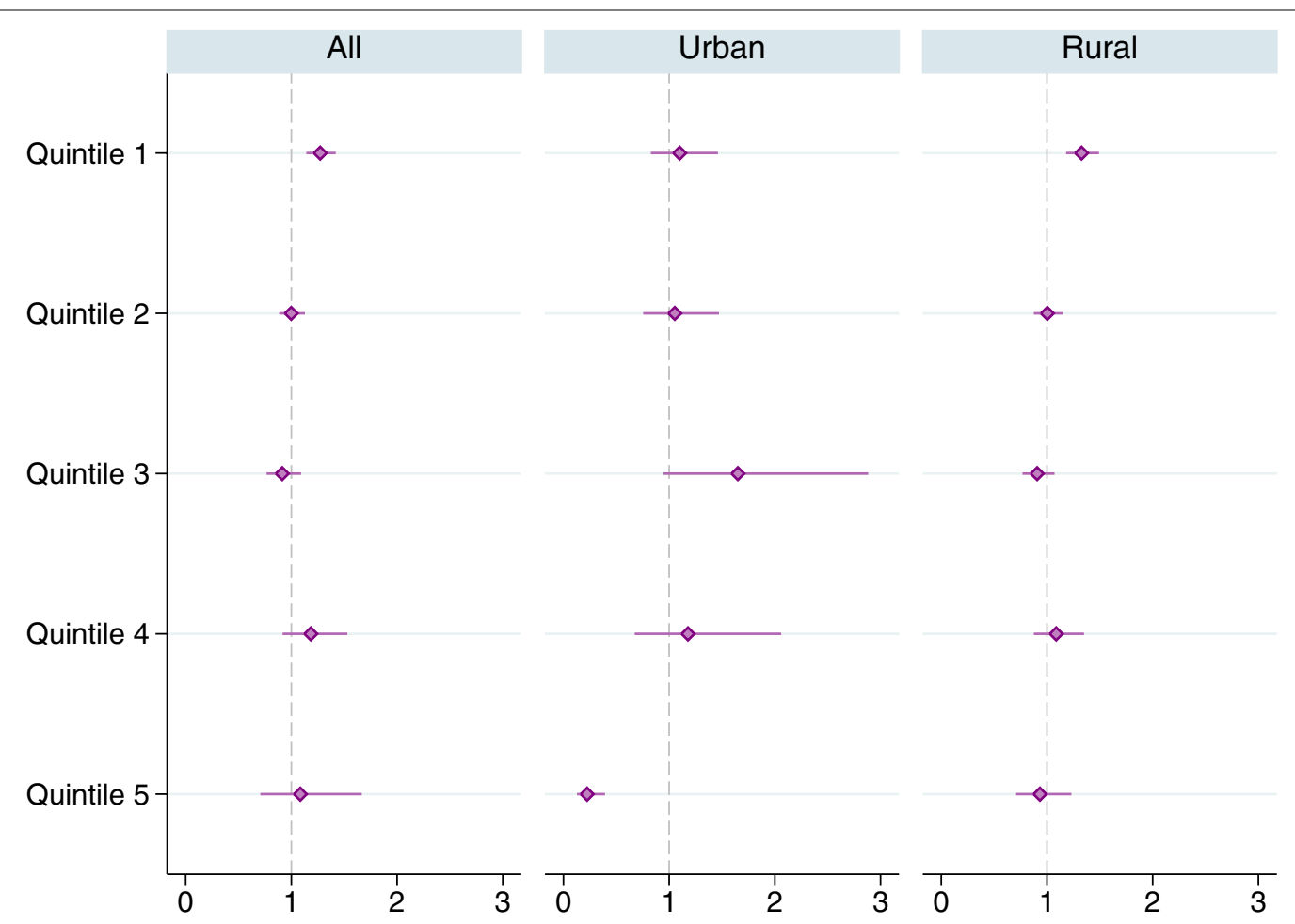

Fig. 2 Adjusted odds ratios for any tobacco use in favor of uncontrolled hypertension, by wealth index quintiles. The horizontal lines around the markers represents $95 \%$ confidence intervals. Estimates were obtained using complex survey weights. Regressions controlled for age group, nutritional status (BMI), education, marital status, urban/rural residence and state fixed effects

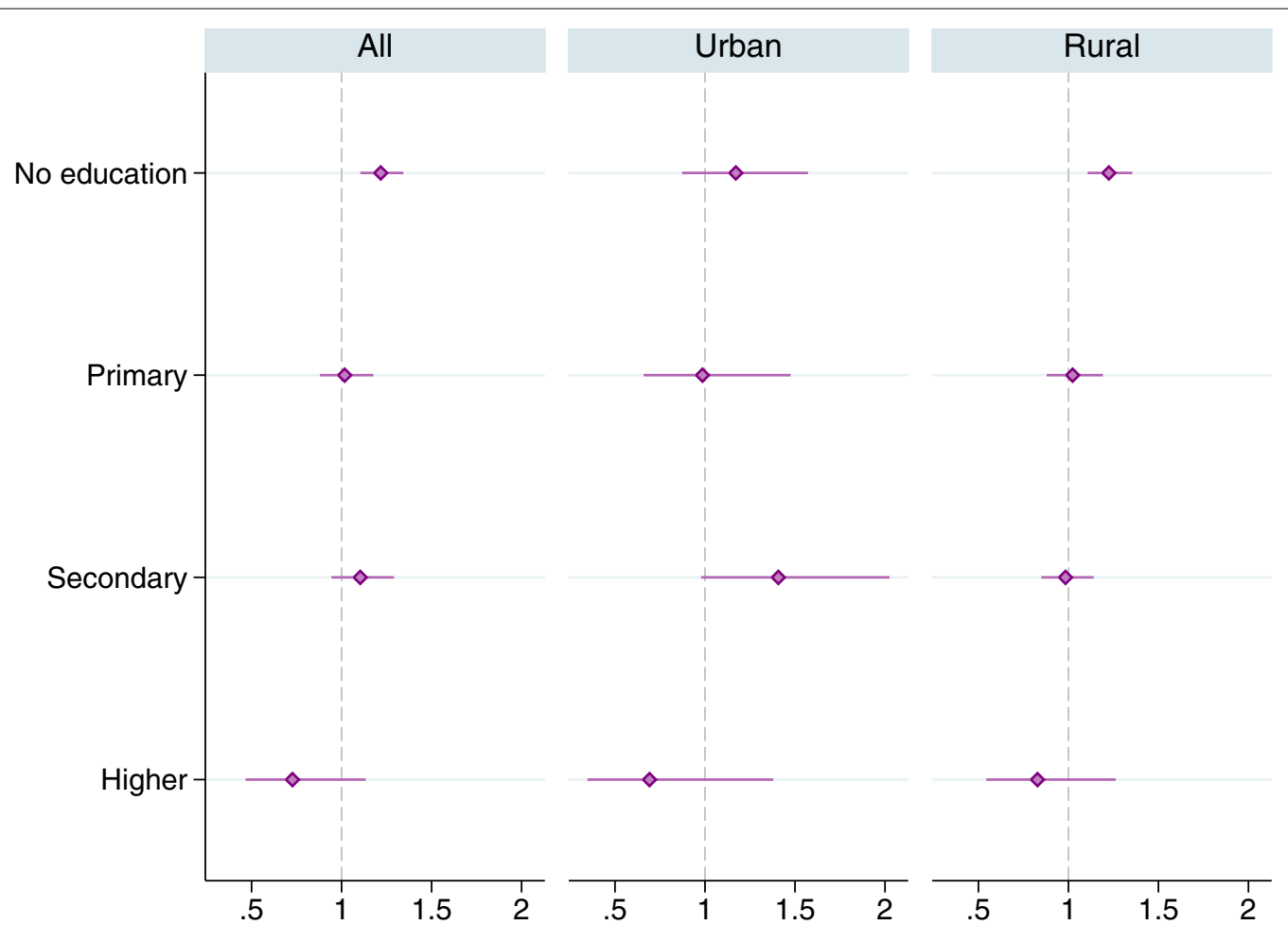

Fig. 3 Adjusted odds ratios for any tobacco use in favor of uncontrolled hypertension, by educational attainment. The horizontal lines around the markers represents $95 \%$ confidence intervals. Estimates were obtained using complex survey weights. Regressions controlled for age group, wealth index quintiles, nutritional status (BMI), marital status, urban/rural residence and state fixed effects 


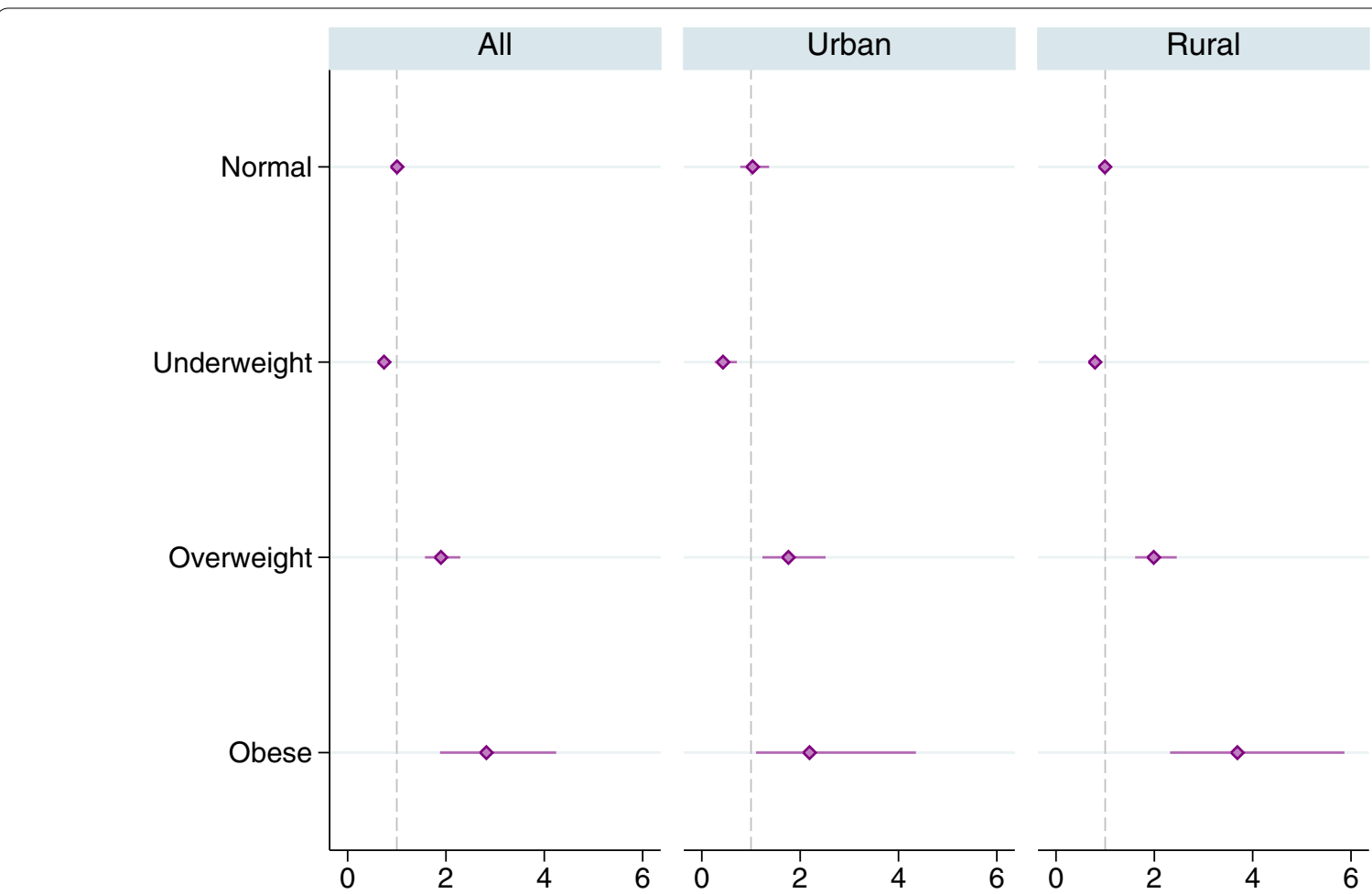

Fig. 4 Adjusted odds ratios for any tobacco use in favor of uncontrolled hypertension, by nutritional status (BMl group). The horizontal lines around the markers represents $95 \%$ confidence intervals. Estimates were obtained using complex survey weights. Regressions controlled for age group, wealth index quintiles, education, marital status, urban/rural residence and state fixed effects

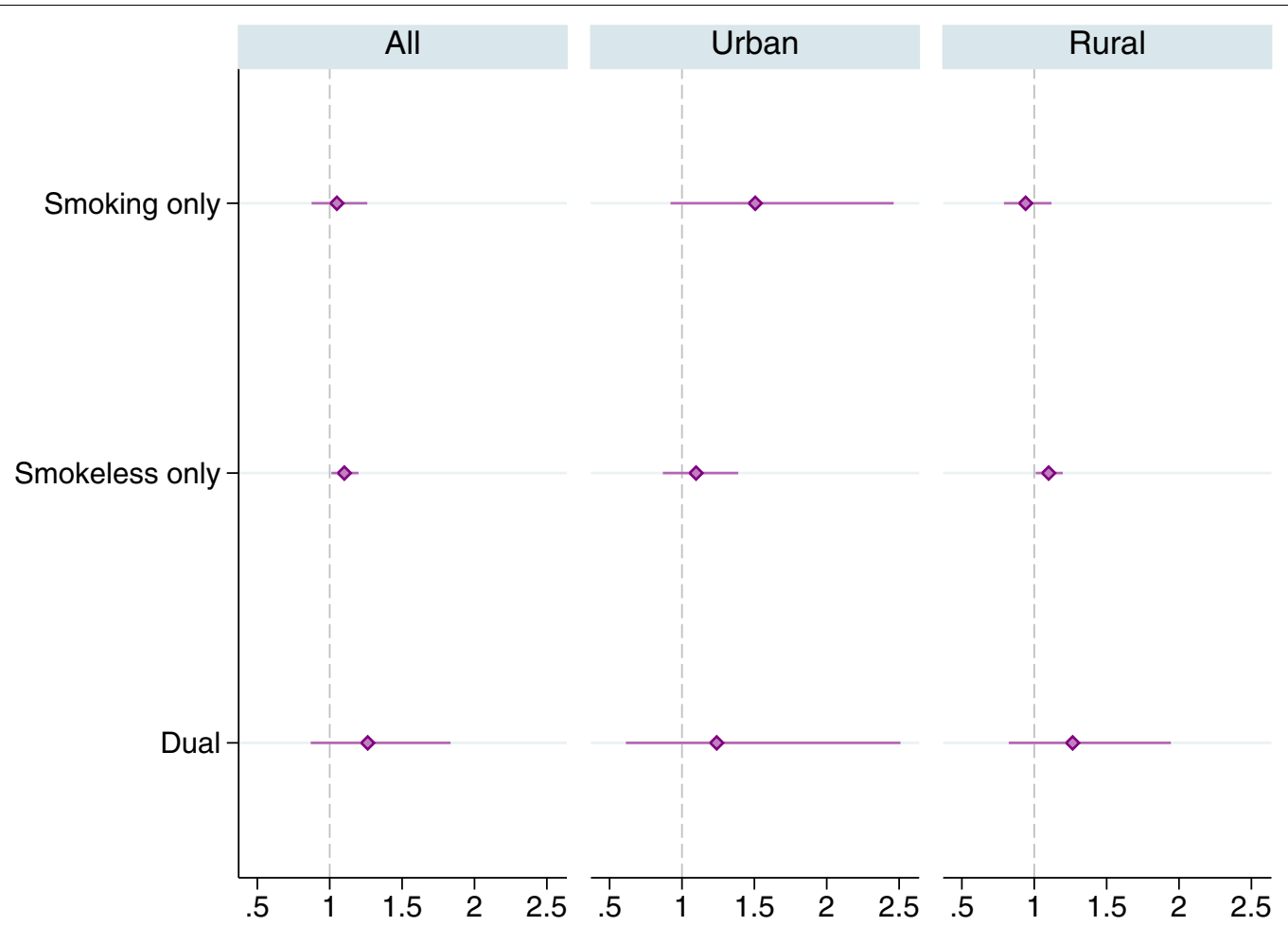

Fig. 5 Adjusted odds ratios for mutually exclusive types of tobacco use in favor of uncontrolled hypertension. The horizontal lines around the markers represents $95 \%$ confidence intervals. Estimates were obtained using complex survey weights. Regressions controlled for age group, nutritional status (BMI), wealth index quintiles, education, marital status, urban/rural residence and state fixed effects 


\section{Abbreviations}

CVD: Cardiovascular disease; NFHS-4: India National Family Health Survey Round 4; DHS: Demographic and Health Surveys; SBP: Systolic blood pressure; DBP: Diastolic blood pressure; BMI: Body mass index.

Not applicable.

\section{Authors' contributions}

BKD designed the study, conducted empirical analyses and prepared the first draft. MJH critically reviewed the results and contributed in finalizing the manuscript. All authors read and approved the final manuscript.

\section{Funding}

None.

\section{Availability of data and materials}

The datasets used and/or analyzed during the current study are available from the USAID's Demographic and Health Surveys (DHS) Program. The DHS datasets are free to download and use upon registering at the DHS program website: https://dhsprogram.com/data/new-user-registration.cfm.

\section{Declarations}

\section{Competing interests}

The authors declare that they have no competing interests.

\section{Ethics approval and consent to participate}

The study used secondary data obtained from the Demographic and Health Surveys (DHS) Program of the USAID.

\section{Consent to publish}

Not applicable.

\section{Author details}

1 Global Noncommunicable Diseases Branch, Division of Global Health Protection, Center for Global Health, Centers for Disease Control and Prevention, 1600 Clifton Road, Atlanta, GA 30329, USA. ${ }^{2}$ Present Address: Institute of Public and Preventive Health, Augusta University, Augusta, GA, USA.

Received: 28 September 2020 Accepted: 23 March 2021

Published online: 09 April 2021

\section{References}

1. Kjeldsen SE. Hypertension and cardiovascular risk: general aspects. Pharmacol Res. 2018;129:95-9.

2. World Health Organization. Cardiovascular diseases (CVDs). Geneva: WHO; 2017. https://www.who.int/news-room/fact-sheets/detail/cardi ovascular-diseases-(cvds). Accessed 2 July 2019.

3. Zhou D, Xi B, Zhao M, Wang L, Veeranki SP. Uncontrolled hypertension increases risk of all-cause and cardiovascular disease mortality in US adults: the NHANES III Linked Mortality Study. Sci Rep. 2018;8(1):1-7.

4. Yoder SR, Thornburg LL, Bisognano JD. Hypertension in pregnancy and women of childbearing age. Am J Med. 2009;122(10):890-5.

5. Primatesta P, Falaschetti E, Gupta S, Marmot MG, Poulter NR. Association between smoking and blood pressure: evidence from the health survey for England. Hypertension. 2001;37(2):187-93.

6. Bolinder G, Ahlborg B, Lindell J. Use of smokeless tobacco: blood pressure elevation and other health hazards found in a large-scale population survey. J Intern Med. 1992;232(4):327-34.

7. Westman E. Does smokeless tobacco cause hypertension? Southern Med J. 1995;88(7):716-20

8. Centers for Disease Control and Prevention. Smoking during pregnancy. Atlanta: CDC; 2018. https://www.cdc.gov/tobacco/basic_infor mation/health_effects/pregnancy/index.htm. Accessed 17 Sep 2019.

9. Bhan N, Srivastava S, Agrawal S, Subramanyam M, Millett C, Selvaraj S, et al. Are socioeconomic disparities in tobacco consumption increasing in India? A repeated cross-sectional multilevel analysis. BMJ Open. 2012;2(5):e001348.
10. Caleyachetty R, Tait CA, Kengne AP, Corvalan C, Uauy R, EchouffoTcheugui JB. Tobacco use in pregnant women: analysis of data from Demographic and Health Surveys from 54 low-income and middleincome countries. Lancet Glob Health. 2014;2(9):e513-20.

11. Shrestha N, Mehata S, Pradhan PMS, Joshi D, Mishra SR. A nationally representative study on socio-demographic and geographic correlates, and trends in tobacco use in Nepal. Sci Rep. 2019;9(1):1-11.

12. Pradhan MR, Patel SK, Prusty RK. Pattern and predictors of tobacco use in India: evidence from National Family Health Survey (2015-2016). J Health Manag. 2019;21(4):510-24.

13. Sreeramareddy CT, Harper $\mathrm{S}$. Trends in educational and wealth inequalities in adult tobacco use in Nepal 2001-2016: secondary data analyses of four demographic and health surveys. BMJ Open. 2019;9(9):e029712.

14. Andriani H, Putri S, Kosasih Rl, Kuo HW. Parental smoking and underfive child mortality in Southeast Asia: evidence from demographic and health surveys. Int J Environ Res Public Health. 2019;16(23):4756.

15. Sreeramareddy CT, Ramakrishnareddy N. Association of adult tobacco use with household food access insecurity: results from Nepal demographic and health survey, 2011. BMC Public Health. 2018;18(1):48.

16. Caleyachetty R, Echouffo-Tcheugui JB, Stephenson R, Muennig P. Intimate partner violence and current tobacco smoking in low-to middleincome countries: individual participant meta-analysis of 231,892 women of reproductive age. Global Public Health. 2014;9(5):570-8.

17. Prenissl J, Manne-Goehler J, Jaacks LM, Prabhakaran D, Awasthi A, Bischops AC, et al. Hypertension screening, awareness, treatment, and control in India: a nationally representative crosssectional study among individuals aged 15 to 49 years. PLoS Med. 2019;16(5):e1002801.

18. Chowdhury MAB, Epnere K, Haque MA, Mkuu RS. Urban rural differences in prevalence and risk factors of self-reported hypertension among Kenyan women: a population-based study. J Hum Hypertens. 2020; https://doi.org/10.1038/s41371-020-00435-X.

19. Yaya S, Ekholuenetale M, Bishwajit G. Differentials in prevalence and correlates of metabolic risk factors of non-communicable diseases among women in sub-Saharan Africa: evidence from 33 countries. BMC Public Health. 2018;18(1):1168.

20. Talukdar D, Tripathi M, Tripathi $\bigvee$, Teelucksingh S. Prevalence and associated factors of undiagnosed hypertension among women aged 15-49 years in India: an analysis of National Family Health Survey-4 data. J Hum Hypertens. 2020; https://doi.org/10.1038/s41371-020-0384-7.

21. Oyekale AS. Effect of obesity and other risk factors on hypertension among women of reproductive age in Ghana: an instrumental variable probit model. Int J Environ Res Public Health. 2019;16(23):4699.

22. Corsi DJ, Subramanian S. Socioeconomic gradients and distribution of diabetes, hypertension, and obesity in India. JAMA Netw Open. 2019;2(4):e190411-e190411.

23. Rauniyar SK, Rahman MM, Rahman MS, Abe SK, Nomura S, Shibuya K. Inequalities and risk factors analysis in prevalence and management of hypertension in India and Nepal: a national and subnational study. BMC Public Health. 2020;20(1):1-11.

24. Datta B, Husain MJ. Spousal alcohol consumption and female hypertension status: evidence from Nepal. Public Health. 2020;185:312-7.

25. Jeha D, Usta I, Ghulmiyyah L, Nassar A. A review of the risks and consequences of adolescent pregnancy. J Neonatal-Perinat Med. 2015;8(1):1-8.

26. Lean SC, Derricott $H$, Jones RL, Heazell AE. Advanced maternal age and adverse pregnancy outcomes: a systematic review and meta-analysis. PLoS ONE. 2017;12(10):e0186287.

27. Khalil A, Syngelaki A, Maiz N, Zinevich Y, Nicolaides KH. Maternal age and adverse pregnancy outcome: a cohort study. Ultrasound Obstetr Gynecol. 2013;42(6):634-43.

28. World Health Organization. GATS2 (Global Adult Tobacco Survey) Fact Sheet, India, 2016-17. Geneva:WHO; 2018. https://www.who.int/ tobacco/surveillance/survey/gats/GATS_India_2016-17_FactSheet.pdf. Accessed 2 July 2029.

29. Gupta R, Gaur K, Ram CVS. Emerging trends in hypertension epidemiology in India. J Hum Hypertens. 2019;33(8):575-87.

30. James PR, Nelson-Piercy C. Management of hypertension before, during, and after pregnancy. Heart. 2004;90(12):1499-504.

31. Montgomery AL, Ram U, Kumar R, Jha P, Collaborators MDS, et al. Maternal mortality in India: causes and healthcare service use based on a nationally representative survey. PLoS ONE. 2014;9(1):e83331. 
32. Blencowe H, Cousens S, Jassir FB, Say L, Chou D, Mathers C, et al. National, regional, and worldwide estimates of stillbirth rates in 2015, with trends from 2000: a systematic analysis. Lancet Glob Health. 2016;4(2):e98-108.

33. Aminu M, Unkels R, Mdegela M, Utz B, Adaji S, Van Den Broek N. Causes of and factors associated with stillbirth in low-and middle-income countries: a systematic literature review. BJOG Int J Obstetr Gynaecol. 2014;121:141-53.

34. Wisborg K, Kesmodel U, Henriksen TB, Olsen SF, Secher NJ. Exposure to tobacco smoke in utero and the risk of stillbirth and death in the first year of life. Am J Epidemiol. 2001;154(4):322-7.

35. International Institute for Population Sciences (IIPS) and ICF. National Family Health Survey (NFHS-4), 2015-16: India. IIPS Mumbai, India; 2017.

36. National Cancer Institute and Centers for Disease Control and Prevention. Smokeless Tobacco and Public Health: A Global Perspective. Bethesda, MD: Department of Health and Human Services, Centers for Disease Control and Prevention and National Institutes of Health, National Cancer Institute; 2014. NIH Publication No. 14-7983.

37. Piano MR, Benowitz NL, FitzGerald GA, Corbridge S, Heath J, Hahn E, et al. Impact of smokeless tobacco products on cardiovascular disease: implications for policy, prevention, and treatment: a policy statement from the American Heart Association. Circulation. 2010;122(15):1520-44.
38. Ram U, Jha P, Ram F, Kumar K, Awasthi S, Shet A, et al. Neonatal, 1-59 month, and under-5 mortality in 597 Indian districts, 2001 to 2012: estimates from national demographic and mortality surveys. Lancet Glob Health. 2013;1(4):e219-26.

39. Vora KS, Mavalankar DV, Ramani K, Upadhyaya M, Sharma B, lyengar S, et al. Maternal health situation in India: a case study. J Health Popul Nutr. 2009;27(2):184

40. Zera C, McGirr S, Oken E. Screening for obesity in reproductive-aged women. Prevent Chron Dis. 2011:8(6):A125.

41. Bhan N, Karan A, Srivastava S, Selvaraj S, Subramanian S, Millett C. Have socioeconomic inequalities in tobacco use in India increased over time? Trends from the national sample surveys (2000-2012). Nicotine Tob Res. 2016;18(8):1711-8.

\section{Publisher's Note}

Springer Nature remains neutral with regard to jurisdictional claims in published maps and institutional affiliations.
Ready to submit your research? Choose BMC and benefit from:

- fast, convenient online submission

- thorough peer review by experienced researchers in your field

- rapid publication on acceptance

- support for research data, including large and complex data types

- gold Open Access which fosters wider collaboration and increased citations

- maximum visibility for your research: over $100 \mathrm{M}$ website views per year

At BMC, research is always in progress.

Learn more biomedcentral.com/submissions 